\title{
Electrocardiographic characteristics of neurocirculatory asthenia during everyday activities
}

\author{
DAN TZIVONI, ZVI STERN, ANDRE KEREN, SHLOMO STERN \\ From the Heiden Department of Cardiology, Bikur Cholim Hospital, The Department of Medicine A, \\ Hadassah Hospital; and the Hebrew University-Hadassah Medical School, ferusalem, Israel
}

SUMMARY We describe the electrocardiographic changes during everyday activities recorded by ambulatory electrocardiographic monitoring in 67 patients with neurocirculatory asthenia. The findings were compared with the results of ambulatory monitoring in 33 healthy controls. We observed episodes of sinus tachycardia $>120 /$ min unrelated to effort in 60 of the patients, 35 had frequent episodes of pronounced sinus arrhythmia, 16 showed transient ST depression, and six transient ST elevation. All these changes appeared during the patients' routine activities, without any unusual exertion and frequently at rest. Periods of sinus tachycardia and sinus arrhythmia were recorded from the patients during sleep. Cardiac arrhythmias, especially ventricular premature beats, were also much more common in those with neurocirculatory asthenia than in the control subjects. These findings indicate that ambulatory electrocardiographic monitoring provides important information on the electrocardiographic characteristics of patients with neurocirculatory asthenia and helps to establish this diagnosis in obscure cases.

Neurocirculatory asthenia is a multisystemic disease involving the cardiovascular, nervous, and respiratory systems described by $\mathrm{Da}$ Costa $^{1}$ as "the irritable heart of the soldiers" during the American Civil War. Since then, it has been detected in soldiers and other young adults in several countries ${ }^{23}$ and called "soldier's heart", "effort syndrome", 3 or "Da Costa's syndrome", 4 but recently the name neurocirculatory asthenia has become the most popular. The most prominent manifestation of this syndrome is palpitation, but many patients also suffer from praecordial pains, anxiety, dyspnoea, fatigue, and other non-specific complaints. Among civilians, it is twice as common in women as in men. ${ }^{5}$ The onset of the symptoms is usually between the ages of 20 and 30 . The haemodynamic features of the disease are high cardiac output, reduced peripheral flow, ${ }^{6}$ and sinus tachycardia, both at rest and in an erect position. These features tend to be exaggerated during effort. ${ }^{5}$ Frequently, fluctuations in blood pressure are pronounced. ${ }^{8}$ The patient's physical condition is often poor; this can be improved by exercise. ${ }^{910}$ In many of the patients ST-T changes in the electrocardiogram are evoked by a change of position ${ }^{11}$ or by effort testing. ${ }^{8}$ Therefore many of them are erroneously Received for publication 11 January 1980 diagnosed as suffering from organic heart disease, for example myocardial ischaemia or myocarditis.

In spite of the above quoted studies, no strict criteria for the diagnosis of neurocirculatory asthenia have been established as yet. The existence of a rapid resting heart rate during casual examination during the day is a generally accepted feature on which this diagnosis is based. ${ }^{4}$ There are, however, no reliable data on the behaviour of heart rate and other electrocardiographic features in such subjects under "physiological" conditions during everyday activities, emotional stress, or sleep. In this study we describe the heart rate, rhythm, and ST-T changes in patients with neurocirculatory asthenia during their daily activities, recorded by ambulatory electrocardiographic monitoring.

\section{Patients and methods}

In this study we included 67 patients aged 18 to 35 years (mean 27) in whom the diagnosis of neurocirculatory asthenia was established clinically. The diagnosis was based upon the usually accepted definitions and characteristics of somatic symptoms. ${ }^{12}$ In our patients, palpitation was experienced by 45 patients, chest pain by 17 patients, hyperventilation and dyspnoea by 27 patients, anxiety by 26 patients, and vague praecordial 
symptoms and dull pressure by 32 patients. The complaints are detailed in Table 1. Physical examination and chest $x$-rays in all patients revealed no signs of organic heart or lung disease. Routine resting electrocardiograms showed sinus tachycardia above $100 / \mathrm{min}$ in 17 patients, ST depression of the "junctional" type in six patients, and flat or inverted $T$ waves in 10 patients. No ectopic activity was detected in the routine electrocardiograms. Thyrotoxicosis, mitral valve prolapse, hypertrophic subaortic stenosis, and anaemia were excluded.

A group of 33 individuals served as a control group. They comprised 22 men and 11 women with ages ranging from 24 to 34 years (mean 29). All volunteered for the test after being examined by one of our team at the gynaecology or gastroenterology outpatient clinics. None of them suffered from any cardiovascular symptoms and physical examinination and electrocardiograms did not disclose any cardiac or lung abnormalities. All of them were employed but not in medical or paramedical work; they performed their usual daily activities during the day of the monitoring. The length of sleep was the usual average for people of similar age.

Ambulatory electrocardiographic monitoring was performed from one morning to the next both in the group of patients and in the controls. The examinees were requested to follow their usual daily routine, and to keep a meticulous diary of all activities and possible symptoms. These were subsequently related to the electrocardiographic findings. The mode of operating the ambulatory electrocardiographic monitoring system, the positioning of the electrodes, and the technique of interpretation have been detailed in previous reports. ${ }^{13-15}$ The Avionics system used in this study was checked for its low-frequency response which fulfilled the American Heart Association (AHA) requirements and recorded satisfactorily the ST-T segment. The magnetic tapes were scanned visually by a trained technician both for arrhythmias and ST-T alterations and the final interpretation was always confirmed by a physician.

Table 1 Complaints of patients with neurocirculatory asthenia

\begin{tabular}{ll}
\hline Complaints & No. of patients \\
\hline Palpitation & 45 \\
Praecordial symptoms & 32 \\
Fatigue & 28 \\
Dyspnoea & 27 \\
Anxiety & 26 \\
Praecordial pain & 17 \\
Dizziness & 11 \\
Other (sweating, headaches, etc.) & 12 \\
\hline
\end{tabular}

Table 2 Electrocardiographic findings on monitoring in patients with neurocirculatory asthenia and in control group

\begin{tabular}{llll}
\hline & & $\begin{array}{l}\text { NCA } \\
(67 \text { patients })\end{array}$ & $\begin{array}{l}\text { Control } \\
\text { (33 subjects) }\end{array}$ \\
\hline $\begin{array}{l}\text { Episodes of sinus } \\
\text { tachycardia without } \\
\text { physical effort }\end{array}$ & & \\
& $>150 / \mathrm{min}$ & 23 & - \\
$>120 / \mathrm{min}$ & 60 & 4 \\
$>100 / \mathrm{min}$ & 67 & 8 \\
\hline $\begin{array}{l}\text { Episodes of sinus } \\
\text { bradycardia }\end{array}$ & $<35 / \mathrm{min}$ & 14 & 1 \\
$\begin{array}{c}\text { Episodes of sinus } \\
\text { tachycardia during } \\
\text { sleep }\end{array}$ & $>90 / \mathrm{min}$ & 30 & 3 \\
$\begin{array}{c}\text { Episodes of sinus } \\
\text { arrhythmia }\end{array}$ & 35 & 4 \\
\hline
\end{tabular}

As in all our other investigations dealing with ambulatory electrocardiographic monitoring, control electrocardiograms were recorded in the supine and erect positions and during hyperventilation. These would reveal any changes caused by posture or respiration.

\section{Results}

\section{HEART RATE}

The most consistent finding in patients with neurocirculatory asthenia was the tendency towards sinus tachycardia (Table 2). In 23 of the patients frequent episodes of a heart rate of above $150 / \mathrm{min}$ were documented during their daily routine, apparently without undue physical effort. None of the control subjects reached such a heart rate during daily activities. In 60 of the 67 patients, periods with a heart rate of above $120 / \mathrm{min}$ occurred repeatedly, and all 67 had episodes of sinus tachycardia faster than $100 / \mathrm{min}$ during the day of monitoring. In the control subjects only four attained a heart rate above $120 / \mathrm{min}$, while eight reached heart rates of more than 100 /min without undue effort. During undisturbed sleep at night, periods of sinus tachycardia between 90 and 120/ min were observed in 30 patients with neurocirculatory asthenia and in only three subjects in the control group.

Sinus arrhythmia, defined as variations in cycle length exceeding the upper limit of $120 \mathrm{~ms}$ between the longest and shortest cardiac cycles, ${ }^{16}$ was documented during usual daily activities in 35 of the patients. Up to 20 episodes each day of the nonphasic (nonrespiratory) form ${ }^{16}$ were observed. The undue acceleration of the pulse was usually unconnected with change of posture or physical effort. In 20 of the patients the sinus arrhythmia was even more obvious during sleep. In the control 


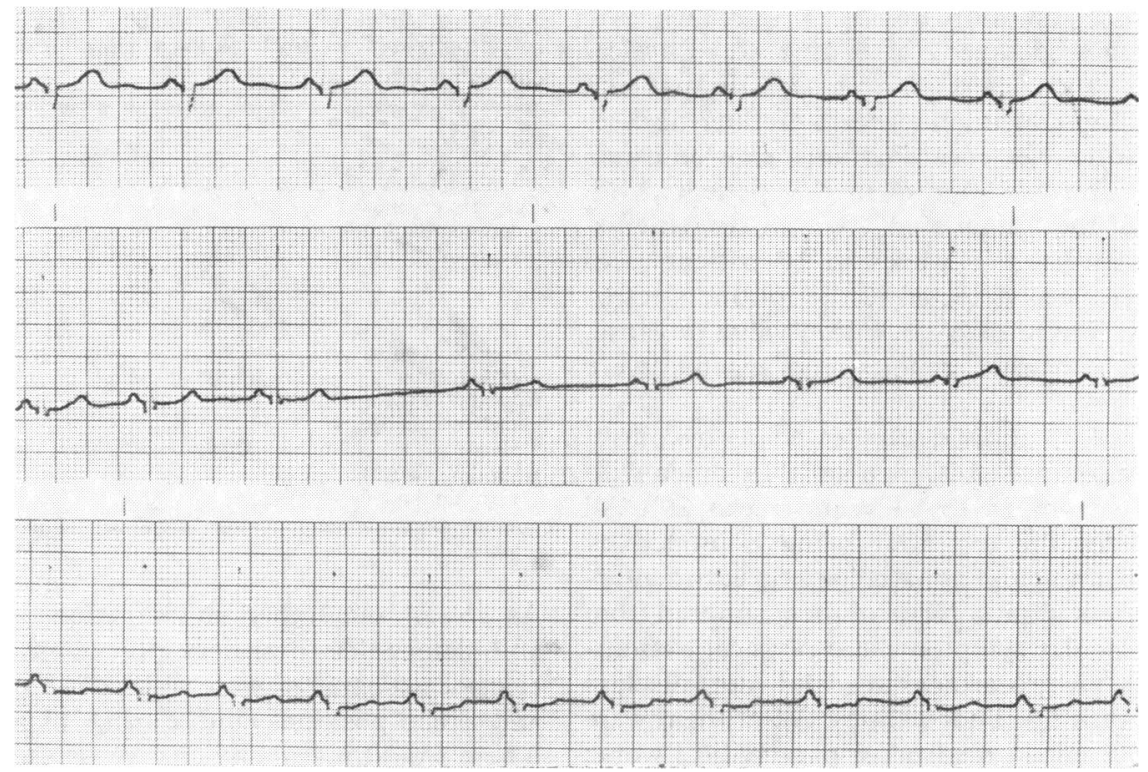

Fig. 1 Variations in sinus rate in a patient with neurocirculatory asthenia recorded during a 24 hour period. Upper panel: normal sinus rhythm. Middle panel: pronounced sinus arrhythmia. Lower panel: sinus tachycardia at rest.

group only four subjects showed such sinus arrhythmia during the monitoring period. Representative electrocardiograms are illustrated in Fig. 1.

\section{RHYTHM DISTURBANCES}

Disturbances in cardiac rhythm were observed more frequently in patients with neurocirculatory asthenia than in control subjects (Table 3). Ventricular premature beats were detected in 12 patients but in only three control subjects. One patient with neurocirculatory asthenia also had a short bout of ventricular tachycardia (Fig. 2). Ectopic atrial activity was found in five patients and one patient had transient nodal rhythm.

\section{ST-T SEGMENT ALTERATIONS}

Forty-six of the 67 patients with neurocirculatory asthenia had ST-T changes during the monitoring period. The types of the ST-T changes are detailed in Table 4. The most common findings were flattening or inversion of the $\mathrm{T}$ wave (Fig. 3). ST segment depression of the "junctional" or J point type (Fig. 4) was found in 12 patients. Segmental downsloping or horizontal ST depression 0.5 to $1.0 \mathrm{~mm}$, using the PR segment as the baseline reference (Fig. 3), was found in four patients. All four patients underwent thallium-201 stress testing which was normal in all, indicating absence of coronary artery disease. Both types of ST changes occurred only when the heart rate was above $110 / \mathrm{min}$. In the controls, the "junctional" type of ST depression was seen in three subjects, but the "segmental" type in none. ST elevation of $1 \mathrm{~mm}$ or more, lasting for at least 12 seconds (observed during a period when the electrocardiograph recording had a stable isoelectric line and the QRS

Table 3 Arrhythmias found in 67 patients with neurocirculatory asthenia and 33 control subjects

\begin{tabular}{|c|c|c|c|c|c|c|c|c|c|}
\hline & $\begin{array}{l}\text { VPB's } \\
>5 / \min \end{array}$ & $\begin{array}{l}V P B ' s \\
5-2 / \min \end{array}$ & $\begin{array}{l}\text { VPB's } \\
\leqslant 1 / \min \end{array}$ & $\begin{array}{l}\text { APB's } \\
>5 / \text { min }\end{array}$ & $\begin{array}{l}A P B \text { 's } \\
5-2 / \min \end{array}$ & $\begin{array}{l}A P B \text { 's } \\
\leqslant 1 / \text { min }\end{array}$ & $\begin{array}{l}\text { APB's } \\
\text { coupled }\end{array}$ & $\begin{array}{l}\text { APB's } \\
\text { blocked }\end{array}$ & $\begin{array}{l}\text { Transient nodal } \\
\text { rhythm }\end{array}$ \\
\hline $\begin{array}{l}\text { Neurocirculatory } \\
\text { asthenia }\end{array}$ & 2 & 4 & 6 & 1 & 1 & 1 & 1 & 1 & 1 \\
\hline Control & 1 & 1 & 1 & - & - & 1 & - & - & - \\
\hline
\end{tabular}

VPB, ventricular premature beat; APB, atrial premature beat.

The figures concerning the frequency of ectopic beats relate to the most frequent ectopic activity observed during the 24 hour monitoring period. 


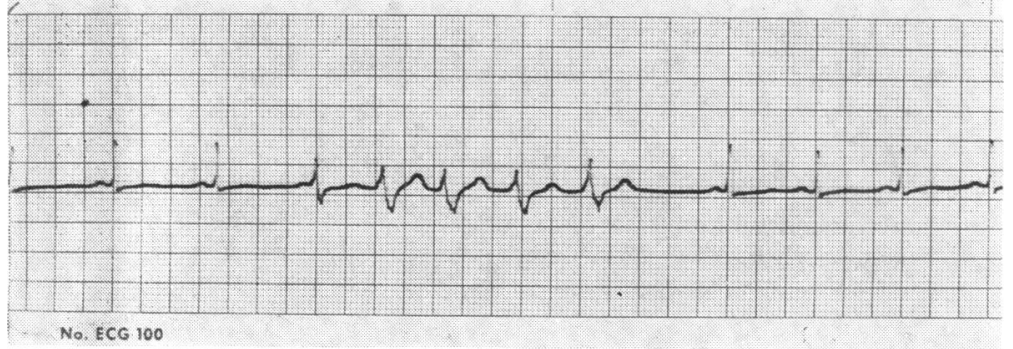

Fig. 2 Short bout of ventricular tachycardia in a 34-year-old patient with neurocirculatory asthenia.

complexes were identical with those preceding the ST elevation), was seen in six patients with neurocirculatory asthenia and in none of the control subjects; in three of the patients the ST elevation occurred during undisturbed sleep (Fig. 5).

\section{Discussion}

Neurocirculatory asthenia is a disease of young adults, featured by distressing symptoms such as palpitation and chest pain. Because of the variety of the symptoms, the syndrome is not easily diagnosed. With the use of the 24-hour ambulatory electrocardiographic monitoring technique we examined a series of 67 patients in their normal environment and during their usual routine activities. We demonstrated that the tendency towards sinus tachycardia in neurocirculatory asthenia prevails not only during physical effort, but is present also during quiet activity and even during rest. These episodes of sinus tachycardia unprovoked by physical effort seem to us to be the characteristic feature of neurocirculatory asthenia, related probably to the beta-adrenergic over-

Table $4 S T-T$ changes found in 67 patients with neurocirculatory asthenia and 33 control subjects

\begin{tabular}{lll}
\hline$S T$ - $T$ changes & $\begin{array}{l}\text { No. of } \\
\text { NCA patients }\end{array}$ & $\begin{array}{l}\text { No. of } \\
\text { control subjects }\end{array}$ \\
\hline $\begin{array}{l}\text { ST depression } \\
\text { segmental (horizontal or } \\
\quad \text { downsloping) }\end{array}$ & 16 & 3 \\
$\quad$ junctional ("J point") & 4 & - \\
Flat T & 12 & 3 \\
Biphasic T & 25 & 4 \\
Inverted T & 3 & 1 \\
ST elevation & 27 & 5 \\
\hline
\end{tabular}

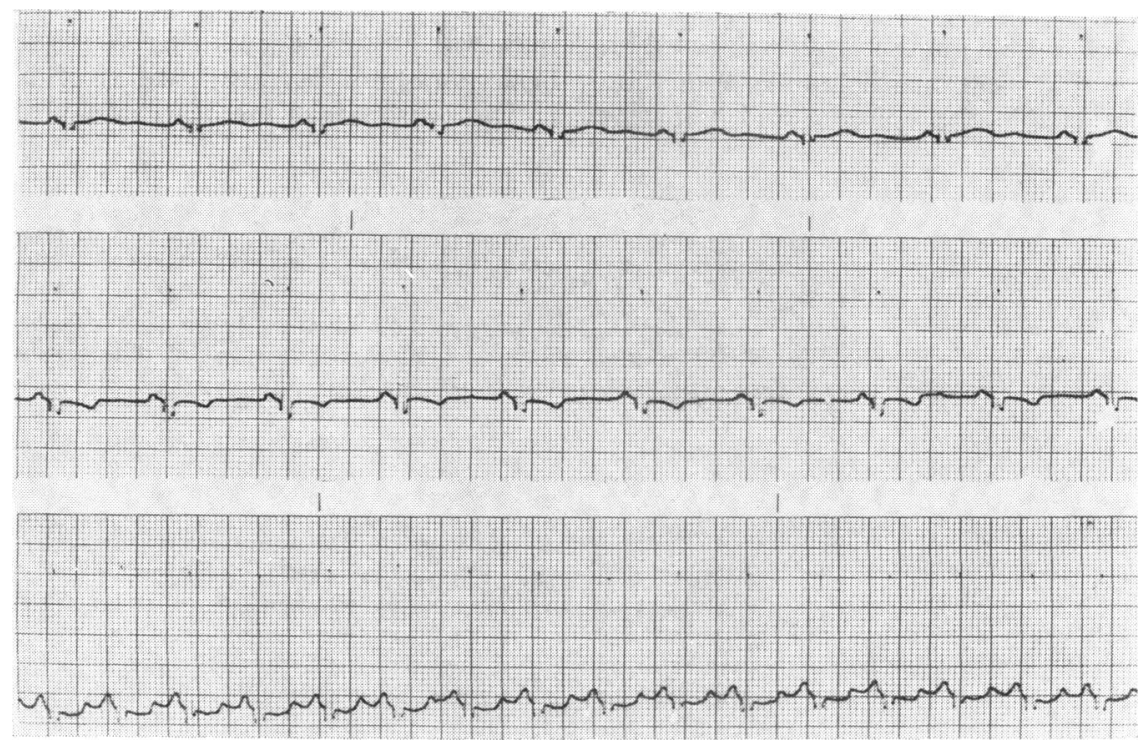

Fig. 3 Variations in $S T$ and $T$ waves in a patient with neurocirculatory asthenia. Upper panel: electrocardiogram during most of the day. Middle panel: inversion of $T$ wave at rest. Lower panel: segmental $S T$ depression during driving associated with sinus tachycardia. 


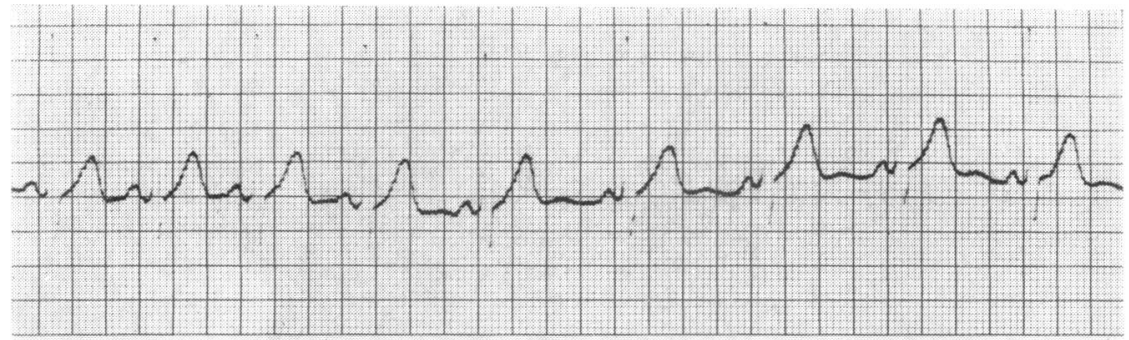

No. ECG 100

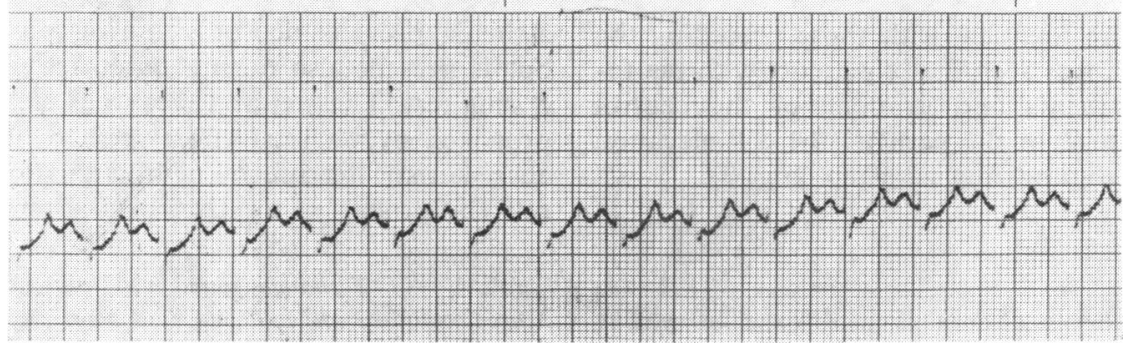

Fig. 4 functional type of $S T$ depression in a patient with neurocirculatory asthenia. Lower panel: recorded while walking; normal electrocardiogram during most of the day (upper panel).

activity existing in this syndrome. ${ }^{17}$ In contrast to our findings, Cohen and White ${ }^{18}$ found only a few abnormalities under basal and rest conditions, and claimed that the anomalies occurred mainly in response to a variety of stresses. This difference may be related to the fact that the important contribution of Cohen and White to the subject of neurocirculatory asthenia in the 1950 s was based on findings in routine electrocardiograms, a method which did not enable the episodic and transient changes prevailing in this syndrome to be detected Although a "great lability of the pulse" has been mentioned by Wood" as a possible feature of $\mathrm{Da}$ Costa's syndrome, the presence of sinus arrhythmia has not yet been properly stressed in published reports dealing with neurocirculatory asthenia. The frequency of sinus arrhythmia documented in more than half of our patients emphasises that this may be an important diagnostic feature of the syndrome.

The behaviour of the heart rate during sleep has
Fig. 5 Ambulatory electrocardiographic monitoring in a 28-yearold woman, showing sinus arrhythmia at rest (upper panel); sinus bradycardia during sleep, associated with $S T$ elevation (middle panel); sinus tachycardia during walking, accompanied by slight $S T$ depression and flattening of $T$ wave (lower panel).
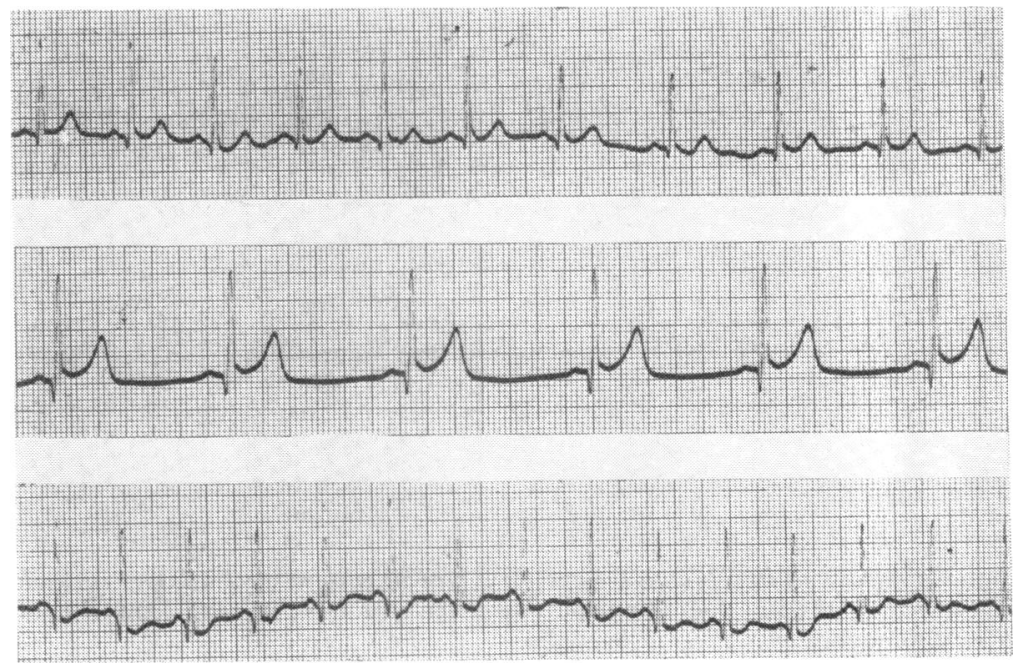
not previously been investigated in patients with neurocirculatory asthenia. Our patients showed a tendency towards episodes of rapid heart rate during sleep as well as during the day. In 30 of the patients periods with a heart rate above $90 / \mathrm{min}$ during undisturbed sleep were observed, accompanied by pronounced sinus arrhythmia and bradycardia. We do not know whether these nocturnal alterations occurred during dreaming periods or changes in body position during sleep. We assume that these changes are an expression of the sympathetic overactivity prevailing also during sleep.

Changes in the ST segment and/or $\mathrm{T}$ wave are frequently described in patients with neurocirculatory asthenia during provocation tests and sometimes even at rest. ${ }^{811}$ In this study we showed that in most patients these alterations appear during quiet activity, without effort or provocation. They seem to be of the so-called "non-specific" type, namely flattening and inversion of $T$ waves, and "junctional" ST depression. "Horizontal" ST depression occurred only in association with sinus tachycardia. The four patients with this feature also had the other characteristics of neurocirculatory asthenia, that is frequent episodes of resting tachycardia and sinus arrhythmia. A normal thallium-201 stress test ruled out coronary disease in all four. Holmgren et al. ${ }^{8}$ also found occasional ST abnormalities in patients with neurocirculatory asthenia. A striking finding in our study was the demonstration of periods of ST segment elevation on monitoring in six of the 67 patients. Transient ST segment elevation has been described previously in normal young subjects, especially in blacks, ${ }^{19}$ and was attributed to autonomic imbalance. In a previous study ${ }^{20}$ of 174 patients evaluated by ambulatory electrocardiographic monitoring for chest pain and/or palpitation, only seven had ST elevation, two of whom were diagnosed as neurocirculatory asthenia. None of our young control subjects demonstrated this finding. ST elevation may be one of the electrocardiographic characteristics of neurocirculatory asthenia which will be detected more often if 24 hour monitoring is used more frequently for these patients.

Exercise testing is a useful method for evaluation of patients with neurocirculatory asthenia. The excessive tachycardia response to effort, the occasional occurrence of ST-T changes during the period of tachycardia, and the frequently reduced physical capacity, are demonstrable by effort testing. ${ }^{8} 11$ Ambulatory electrocardiographic monitoring is capable of detecting these changes and can, in addition, provide data on the behaviour of the heart rate and other electrocardiographic indices unrelated to physical effort. In our opinion, tachycardia during rest is more characteristic of neurocirculatory asthenia than is exercise-induced rapid heart rate, and is more frequently related to patients' symptoms. The relation between the symptoms and the episodes of tachycardia can be demonstrated convincingly by ambulatory electrocardiographic monitoring.

We conclude that ambulatory electrocardiographic monitoring is a useful method for assessing patients known or suspected to have neurocirculatory asthenia. Sinus tachycardia at rest during the day and during sleep, an exaggerated tachycardiac response to physical effort, frequent episodes of severe sinus arrthymia, ST-T changes, and characteristic symptoms all contribute to the correct diagnosis of this syndrome.

\section{References}

1 Da Costa JM. Medical diagnosis. Philadelphia: JB Lippincott, 1864.

2 Myers ABR. On the aetiology and prevalence of diseases of the heart among soldiers. London: J Churchill, 1870.

3 Lewis T. Report upon soldiers returned as cases of "disordered action of the heart" (D.A.H.) or "valvular disease of the heart" (V.D.H.). Spec Rep Ser Med Res Comm 1917; 8.

4 Wood P. Da Costa's syndrome (or effort syndrome). Br Med f 1941; i: 767-72, 805-11, \& 845-51.

5 Cohen ME, White PD. Neurocirculatory asthenia: 1972 concept. Milit Med 1972; 137: 142-4.

6 Juchems RH. Circulation times in patients with neurocirculatory asthenia. Am Heart $\mathcal{F} 1964$; 67: 5837.

7 Holmgren A, Jonsson B, Levander M, Linderholm H, Sjöstrand T, Ström G. Low physical working capacity in suspected heart cases due to inadequate adjustment of peripheral blood flow (vasoregulatory asthenia). Acta Med Scand 1957; 158: 413-36.

8 Holmgren A, Jonsson B, Levander M, Linderholm $H$, Sjöstrand T, Ström G. ECG changes in vasoregulatory asthenia and the effect of physical training. Acta Med Scand 1959; 165: 259-71.

9 Holmgren A, Jonsson B, Levander $\mathrm{M}$, et al. Physical training of patients with vasoregulatory asthenia. Acta Med Scand 1957; 158: 437-46.

10 Holmgren A, Jonsson B, Levander M, et al. Effect of physical training in vasoregulatory asthenia, in $\mathrm{Da}$ Costa's syndrome, and in neurosis without heart symptoms. Acta Med Scand 1959; 165: 89-103.

11 Mann A, Wintner I, Kellerman JJ. The orthostatic test in neurocirculatory asthenia (Hebrew). Harefuah 1973; 84 : 428.

12 Hurst JW, Logne R, Schlant RC, Wenger NK. The heart, arteries and veins. 3rd ed. New York: McGrawHill, 1978: 1805-9.

13 Wolf E, Tzivoni D, Stern S. Comparison of exercise tests and 24-hour ambulatory electrocardiographic 
monitoring in the detection of ST-T changes. $\mathrm{Br}$ Heart F 1974; 36: 90-5.

14 Stern S, Tzivoni D. Early detection of silent ischaemic heart disease by 24-hour electrocardiographic monitoring of active subjects. Br Heart $\mathcal{F} 1974$; 36: 481-6.

15 Stern S, Tzivoni D, Stern Z. Diagnostic accuracy of ambulatory ECG monitoring in ischemic heart disease. Circulation 1975; 52: 1045-9.

16 Hurst JW, Logne R, Schlant RC, Wenger NK. The heart, arteries and veins. 3rd ed. New York: McGrawHill, 1978: 644 .

17 Frohlich ED. Beta adrenergic blockade in the circulatory regulation of hyperkinetic states. $A m \mathcal{F}$ Cardiol 1971; 27: 195-9.
18 Cohen ME, White PD. Life situations, emotions and neurocirculatory asthenia (anxiety neurosis, effort syndrome). Psychosom Med 1951; 13: 335-57.

19 Wasserburger RH, Lorenz TH. The effect of hyperventilation and probantine on isolated RS-T segment and T-wave abnormalities. Am Heart $\mathcal{f}$ 1956; 51 : 666-83.

20 Golding B, Wolf E, Tzivoni D, Stern S. Transient S-T elevation detected by 24-hour ECG monitoring during normal daily activity. Am Heart $\mathcal{f} 1973$; 86: 501-7.

Requests for reprints to Professor Shlomo Stern, Bikur Cholim Hospital, PO Box 492, Jerusalem, Israel. 